\title{
BOI DE MAMÃO NA COMUNIDADE: EDUCAÇÃO, CULTURA POPULAR E AS LINGUAGENS ARTÍSTICO-CULTURAIS
}

Leisla Costa Pereira ${ }^{1}$, Larissa Rocha Soares ${ }^{2}$, Silemar Maria de Medeiros da Silva ${ }^{3}$, Amalhene Baesso Reddig 4

\section{INTRODUÇÃO}

A cultura integrada no contexto social conduz a mudanças e reorganizações, no qual estamos sujeitos a adaptações. Os resultados dessa dinâmica vêm por meio de transformações que, provocadas por diferentes manifestações culturais, se dá através de suas relações, interações e até mesmo distinções. Laraia $(2004$, p.101) diz que "[...] cada sistema cultural está sempre em mudança. Entender essa dinâmica é importante para atenuar o choque entre as gerações e evitar comportamentos preconceituosos". Como sujeitos ativos, somos produzidos por essa cultura ou por culturas, ao mesmo tempo em que somos produtores de cultura. Nossas identidades são constituídas nessas relações, e não se fazem fixas. Esse processo de (re)criação de novas identidades é trazido por Stuart Hall (2005), quando ele defende que a identidade não é tratada como algo inerte, isso é mudado de acordo com a forma como o sujeito é concebido - o que não se dá involuntariamente -, é uma relação que envolve a interação do sujeito com ele mesmo, com o outro e com o mundo.

Em meio a essas modificações é possível que haja a perda de alguns costumes, crenças e até mesmo manifestações culturais que antes faziam parte de um determinado povo. São culturas que marcaram gerações, e que entendemos que não devem ser esquecidas. Como cultura regional catarinense, se destaca o folguedo do Boi de Mamão. Na cultura popular catarinense temos diversas manifestações culturais em vários âmbitos, dentro da religiosidade, da literatura, do artesanato, e tantas outras manifestações populares, como a pesca da pandorga, as danças da festa junina. Temos, ainda, o Boi de Mamão, o Pau de Fita, a Ratoeira,

\footnotetext{
${ }^{1}$ Acadêmica do curso Artes Visuais - Bacharelado da UNESC; bolsista de extensão no projeto Boi de Mamão na Comunidade: Educação, Cultura Popular e as Linguagens Artístico-Culturais - UNESC.

${ }^{2}$ Acadêmica do curso Artes Visuais - Bacharelado da UNESC; bolsista de extensão no projeto Boi de Mamão na Comunidade: Educação, Cultura Popular e as Linguagens Artístico-Culturais - UNESC.

3 Mestre em Educação; Professora da UNESC; Coordenadora do projeto Boi de Mamão na Comunidade: Educação, Cultura Popular e as Linguagens Artístico-Culturais - UNESC.

${ }^{4}$ Mestre em Educação; Professora da UNESC; Coordenadora do projeto Boi de Mamão na Comunidade: Educação, Cultura Popular e as Linguagens Artístico-Culturais - UNESC.
} 
o culto ao Divino Espírito Santo, Terno de Reis, a Farra do Boi, entre outros (FUNDAÇÃO FRANKLIN CASCAES, 2008).

Apresentamos aqui o folguedo do Boi de Mamão e de suas particularidades, a partir do projeto Boi de Mamão na Comunidade: Educação, Cultura Popular e as Linguagens ArtísticoCulturais, desenvolvidas na UNESC. Trata-se de um projeto que vem com o propósito de dar vida novamente ao Boi da FUCRI/UNESC, literalmente "ressuscitá-lo", assim como criar grupos em escolas próximas à universidade, motivando alunos de ensino médio a dançar o Boi.

\section{O BOI DE MAMÃO}

O Boi de Mamão é considerado uma das brincadeiras com mais amplitude do folclore catarinense. Divertida, interativa e leve, a apresentação encanta a todos, desde aqueles que já tiveram contato, assim como os que presenciam/experienciam pela primeira vez. Ele se faz como teatro de rua, manifestação popular que contempla diversas linguagens, um exercício híbrido que nos faz dançar, cantar e explorar um movimento corporal que, enquanto dança, se assusta, se alegra e se envolve em uma brincadeira compartilhada com a comunidade como um todo, num exercício multicultural.

Apesar de todos os estudos ainda pairam dúvidas e controvérsias sobre a origem do Boi de Mamão e seu nome em Santa Catarina. Inicialmente atribui-se aos nordestinos sua transposição para nossa ilha (Florianópolis). Ao mesmo tempo em que Câmara Cascudo (2001) registra no Dicionário do Folclore Brasileiro, no verbete Boi-de-Mamão, que uma pesquisa cuidadosamente feita por Nereu do Vale Pereira em 1996 deixa claro que: "não se pode partir do pressuposto de que o Boi-de-mamão catarinense tenha derivado do Bumbameu-boi nordestino", para Cascudo (2001, p. 71) “comparando os folguedos dos séculos XVIII e XIX, na Espanha, como fonte importantíssima de semelhança ocorrida na organização dos grupos de bois em Santa Catarina".

Outra versão, das mais defendidas, é que veio de Portugal, da região dos Açores (SOARES, 2002). Há também diversos nomes, alguns deles são conhecidos por "bumba-meuboi, boi-bumbá, boi-de-reis, boizinho, boi-da-cara-preta, boi-pintadinho. Boi-calemba, entre outros" (FUNDAÇÃO FRANKLIN CASCAES, 2008, p. 14). Por fim, hoje é reconhecido por Boi-de-Mamão, onde na pressa de terminar o boi antes de uma apresentação, utilizaram um mamão verde para fazer a cabeça, e assim ficando conhecido como Boi de Mamão (SOARES, 
2002). Há também outra hipótese de que é uma derivação de "Boi-mamão", que significaria “boi que mama” (FUNDAÇÃO FRANKLIN CASCAES, 2008).

O vaqueiro e seu boi são indispensáveis no folguedo. Outros principais personagens são: a Cabrinha - alegre e colorida, a Mariana - moça alta e namoradeira, a Bernúncia - que come tudo, inclusive crianças, e o Cavalinho. Pode-se inserir outros personagens, de acordo com a cultura de cada localidade. Há lugares em que foi acrescentado o Jacaré, Macaco, Marimbondo. No Boi de Mamão FUCRI/UNESC têm-se o desejo de implementar o Mineiro, figura de bastante representatividade na cidade de Criciúma.

As pessoas que dançam devem "incorporar" o seu personagem, não limitando-se somente à elas mesmas, mas sim, de fato à atuação, encarnando, se tornando parte do bicho, para assim provocar efetivo encantamento a quem aprecia o folguedo. Com isso, segundo Marcoliva (2012, p. 14):

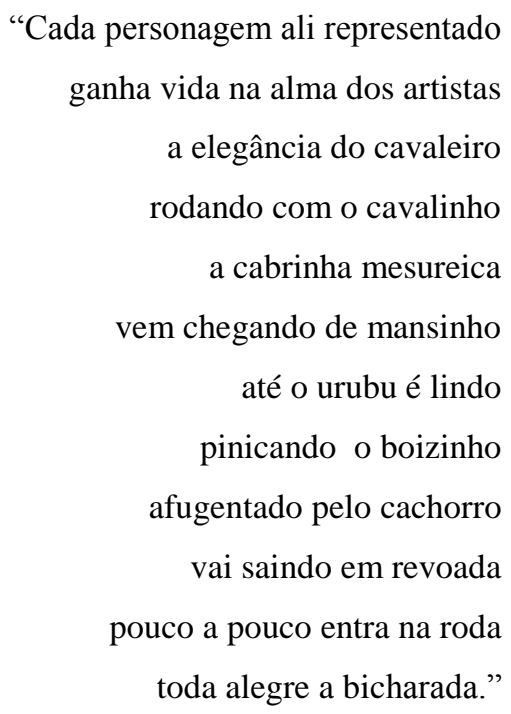

O cantador/puxador desempenha importante papel de orientador, pois por meio de seus versos cantados, improvisados e rimados, ele conta o enredo que compreende a história da morte e ressurreição do Boi. Nesse processo, ele chama a "bicharada" para a roda, onde estes vão adentrando o espaço com seu brilho, magia e alegria. Desse modo, o folguedo do Boi-de-Mamão oportuniza a conquista de novos espaços, de trocas de brincadeiras, alegria, euforia, assim também como um espaço de ensino, pesquisa e extensão, a qual a universidade propõe. Sobre estes fatos, existe também o objetivo de não deixarmos o folguedo ' 'morrer', realizando, assim, a ressurreição do antigo Boi-de-Mamão da FUCRI/UNESC, que foi desenvolvido pelo professor Edi Balod envolvendo funcionários, parceiros e acadêmicos nos anos de 1980 a 1990. 
Com o intuito de (re)significar a importância dessa narrativa, o projeto vai além da universidade, se expandindo para comunidades, assumindo o compromisso de trabalhar a cultura regional e compartilhar com os jovens que a cultura pode-se fazer com práticas coletivas. O projeto visa essa dinâmica, a importância de um trabalho interdisciplinar dentro e fora da universidade. Pensando nesses, aspectos até quando será compartilhado, brincado e vivenciado o Boi de Mamão? As memórias que ficam armazenadas com as pessoas que vivenciam essa experiência e contato, ao qual são passadas de geração em geração, e podem ser também passadas de jovens para jovens? Por que não?

\section{PROJETO BOI DE MAMÃO NA COMUNIDADE: EDUCAÇÃO, CULTURA POPULAR E AS LINGUAGENS ARTÍSTICO-CULTURAIS}

O projeto de extensão Boi de Mamão na Comunidade: Educação, Cultura Popular e as Linguagens Artístico-Culturais estabelece uma relação muito intensa com a cultura popular referente ao folguedo. A inserção na realidade social por meio do projeto visa estimular e garantir o envolvimento dos acadêmicos, dos professores e pesquisadores na discussão e encaminhamento de proposta de ensino, pesquisa e extensão a partir da demanda da própria comunidade. Nesse sentido, vivencia a pesquisa, o ensino e a extensão, prática que a instituição fomenta. "Este elo envolve parcerias e troca de saberes, estabelecidas pelo diálogo entre as partes envolvidas" (CERETTA et al., 2016, p. 8). Estabelecer essa conexão com a comunidade via extensão transcende de forma efetiva, oportunizando o resgate da cultura regional local, culminando em resultados positivos para a pesquisa.

Um folguedo que se constrói a partir de um grupo comprometido com a ressurreição do Boi da FUCRI/UNESC. Esta história moveu um projeto anterior aprovado pelo Edital $\mathrm{N}^{\circ}$ 23/2013, intitulado Boi de Mamão na Comunidade: Reflexões sobre Memória, História, Arte Popular e Identidade Cultural, nos anos de 2014/2015. Os trabalhos contemplaram uma escola pública: Escola de Educação Básica Gov. Heriberto Hulse - Criciúma/SC, onde teve a construção dos seus próprios personagens de Boi de Mamão e enredo. Além do trabalho na escola, o projeto contemplou estudos sobre a história do Boi de Mamão, visando à confecção dos personagens e restauração (que desde 1990 estava desativado) e apresentação do Boi de Mamão FUCRI/UNESC. Uma das ações realizadas foi o I Encontro dos Bois, que contou com a apresentação de diferentes grupos da região realizando a brincadeira com seus Bois de 
Mamão. O Curso de Artes Visuais Licenciatura e Bacharelado tem envolvimento com a participação dos acadêmicos como voluntários.

O projeto atual, nomeado Boi de Mamão na Comunidade: Educação, Cultura Popular e as Linguagens Artístico-Culturais, aprovado pelo Edital No 27/2015, que acontece nos anos de 2016/2017, se renova assumindo o compromisso de continuar essa história, atendendo às demandas da comunidade. As atividades previstas no projeto aprovado vêm sendo pondo em prática: Oficinas de miniaturas dos personagens do Boi-de-Mamão, com alunos do segundo ano em parceria com o Colégio Unesc, mediados pelo professor de artes. Foram promovidos ensaios com os personagens do Boi-de-Mamão da FUCRI/UNESC, no qual os alunos da Escola Gov. Heriberto Hulse foram convidados a estar na Universidade com o propósito de incentivar os alunos do Colégio Unesc a participarem. Com isso, faz-se o diálogo entre as duas escolas, oportunizando troca mútua de vivência dessa manifestação cultural.

Faz-se importante também o exercício de escritas acadêmicas e apresentações em eventos científicos, desenvolvido pelas bolsistas do projeto, algo que oportuniza o registro e documenta nosso processo diante do projeto. O Colégio Unesc é ressaltado nas atividades previstas no cronograma do projeto, sendo considerado um parceiro. Mantemos também a parceria com a Escola de Educação Básica Gov. Heriberto Hulse - Criciúma/SC, ao qual sempre se fez ativa no projeto. Foi feito uma visita técnica ao professor Edi Balod, que foi o precursor do Boi de Mamão nos anos 80 e 90, no qual este conta-nos a história do antigo Boi de Mamão da FUCRI/UNESC. Em meio à visita recebemos a doação de cinco estandartes dos anos de 80 a 90, assim como a cabeça do Boi de Mamão, resgatando a originalidade e engrandecendo essa história marcante que podemos rememorar com a juventude. Confecção, consertos e ornamentação das roupas, restauração das cabeças dos personagens e reparo nas estruturas foram trabalhos constantes, pois priorizamos também a manutenção, no sentido de estarmos sempre em busca de aperfeiçoamentos nas estruturas e roupagem dos personagens. A cantoria do Boi da FUCRI/UNESC está sendo desenvolvida a partir de amplos estudos sobre as cantorias dos diferentes Bois de Santa Catarina. Realizamos em 2016 uma oficina na Semana Acadêmica Integrada do Curso de Artes Visuais, a convite do próprio curso, momento em que propomos a contextualização do enredo, a narrativa, a música, assim como exercícios básicos de dança e passos para os integrantes que deram vida aos personagens. A oficina foi concluída na terceira noite do evento, com um cortejo na $18^{\mathrm{a}}$ Mostra de Orquídeas - Primavera e Paz - UNESC (figura 1). 
Figura 1. Cortejo na $18^{\mathrm{a}}$ Mostra de Orquídeas - Primavera e Paz - UNESC.

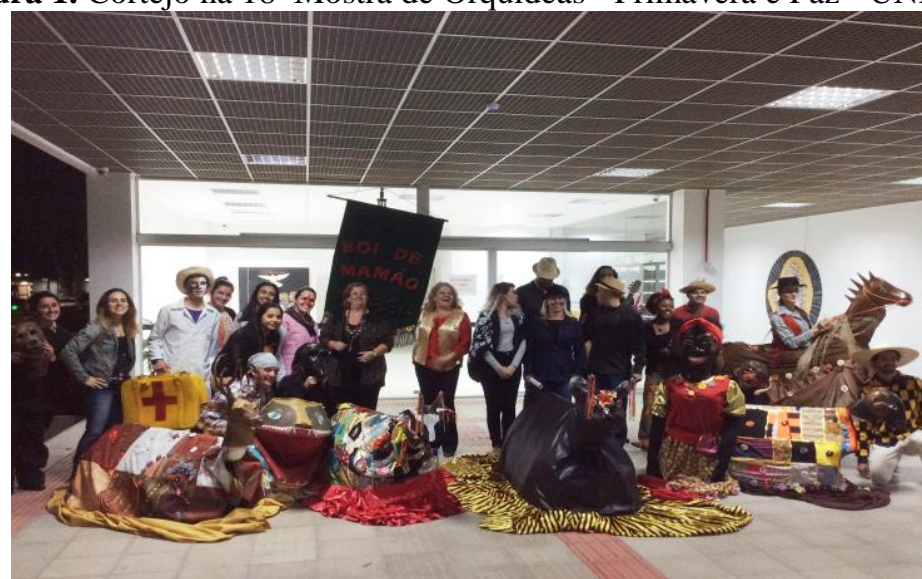

Fonte: Acervo do projeto.

O contato com novas pessoas que se interessaram em estar na oficina nos permitiu novas parcerias, engrandecendo nossas expectativas quanto ao renascimento do Boi-deMamão da FUCRI/UNESC. No final do ano de 2016 tivemos o "II Encontro de Bois" em parceria com o Setor Arte Cultura UNESC. Nesse encontro contamos com a presença do Boide-Mamão da Escola Gov. Heriberto Hulse - Criciúma/SC e Grupo de Cantadores Raízes Culturais/Maracajá (figura 2).

Figura 2. II Encontro de Bois - UNESC.

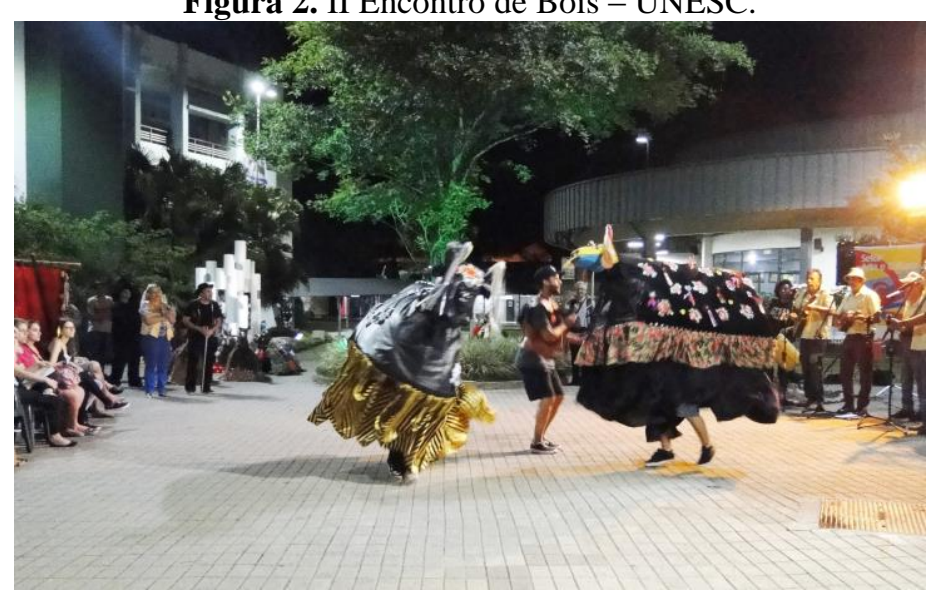

Fonte: Acervo do projeto.

Nesse caso, temos por objetivo principal a efetiva restauração e ressurreição do Boi da FUCRI/UNESC. Além deste desafio, o projeto propõe instrumentalizar acadêmicos e estudantes do ensino médio das escolas parceiras a assumirem o papel de novos formadores populares sobre o enredo do Boi-de-Mamão, em espaços que vão além da própria instituição. 
Com objetivos de promover troca de experiências entre os educadores, educandos e comunidade.

\section{CONSIDERAÇÕES FINAIS}

O projeto Boi-de-Mamão FUCRI/UNESC prossegue de forma significativa com envolvimentos dos universitários junto da comunidade, no qual tem-se o desejo de ver o folguedo presente de forma viva em nossa região. Essa retomada facilita às pessoas o contato com a cultura regional, no sentido de mantê-la viva e em diálogo com a contemporaneidade. Nesse sentido tem importância a figura dos adolescentes e jovens. Motivá-los à brincadeira e ainda reviver o enredo, enaltecendo lembranças a todos que tiverem oportunidade de ver ou brincar/dançar o folguedo.

Além disso, acreditamos que a cultura pode e deve ser trabalhada nas escolas de uma forma mais envolvente, levando os estudantes a se reconhecerem nessas práticas regionais e que se sintam pertencentes a grupos que se manifestam coletivamente sem que sejam apenas apreciadores do fazer dos demais, mas também participantes. Sabemos que essa caminhada está apenas começando, mas já observamos sinais positivos, com essas iniciativas deste projeto de extensão dentro da universidade, o qual vai criando eco com outros folguedos de Boi-de-Mamão que nos procuram, e os que nos acolhem. O comprometimento com a comunidade e escolas faz-se essencial na busca da valorização da cultura regional.

\section{AGRADECIMENTOS}

À Universidade do Extremo Sul Catarinense (UNESC), ao corpo docente, direção e administração por possibilitar através da pesquisa e extensão, com o intuito de promover a qualidade e a sustentabilidade do ambiente de vida. Unidade Acadêmica de Humanidades, Ciências e Educação - UNAHCE, Pró-Reitoria de Pós-Graduação, Ensino e Extensão PROPEX, Escola de Educação Básica Governador Heriberto Hulse, ao Colégio Unesc, ao Arte na Escola - Polo UNESC, Setor Arte e Cultura - UNESC, Curso de Artes Visuais UNESC. A todos os envolvidos de forma geral, voluntários, acadêmicos, funcionários e comunidade pela acessibilidade de poder estar contribuindo no âmbito da cultura regional.

\section{REFERÊNCIAS}

CASCUDO, C. Dicionário do Folclore Brasileiro. 11 ed. São Paulo: Global, 2001. 
CERETTA, L. B. et al. Cartilha de Extensão: Universidade do Extremo Sul Catarinense. Criciúma: EdiUnesc, 2016.

INÁCIO, C.; MARTINS, M. D. A festa do Boi de Mamão. Ilustrações de Marcella Faria de Andrade. Florianópolis: Cuca Fresca, 2013.

FUNDAÇÃO FRANKLIN CASCAES, Equipe técnica da Coordenadoria de Patrimônio Cultural. Roteiro das Manifestações Culturais do Município de Florianópolis. Ilustrações de Maurilo Roberge. 3. ed. Florianópolis: Fundação Franklin Cascaes, 2008. 60 p. il.

HALL, S. A Identidade Cultural na Pós-Modernidade. 10 ed. Rio de Janeiro: DP\&A, 2005 .

LARAIA, R. B. Cultura: Um conceito antropológico. 17 ed. Rio de Janeiro: Jorge Zahar, 2004.

MARCOLIVA. De A à Z: Uma história poética da brincadeira do Boi-de-mamão na Ilha de Santa Catarina. Ilustrações de Denilson Antônio. Florianópolis: Bernúncia, 2012.

SOARES, D. Folclore Catarinense. Florianópolis: Editora da UFSC, 2002. 